\title{
Satellite Tracking and Analysis Tool (STAT): an integrated system for archiving, analyzing and mapping animal tracking data
}

\author{
M. S. Coyne ${ }^{1,2, *}$, B. J. Godley \\ ${ }^{1}$ Marine Geospatial Ecology Lab, Nicholas School of the Environment and Earth Sciences, Duke University, Durham, \\ North Carolina 27708-0328, USA \\ ${ }^{2}$ SEATURTLE.ORG, 1 Southampton Place, Durham, North Carolina 27705, USA \\ ${ }^{3}$ Marine Turtle Research Group, Center for Ecology and Conservation, University of Exeter in Cornwall, Penryn, \\ Cornwall, TR10 9EZ, UK
}

\begin{abstract}
Despite the obvious power and advantages of the Argos system to track animals by satellite, the data generated are difficult for many biologists to exploit. A broad range of skills is required to efficiently download, collate, filter and interpret Argos data. Integration of animal movements with other physical (e.g. remote sensing imagery) and anthropogenic (e.g. fishery distributions) datasets presents additional technical and computing challenges. The Satellite Tracking and Analysis Tool (STAT) is a freely available system designed for biologists who work on animal tracking; it includes a set of standardized tools and techniques for data management, analysis, and integration with environmental data. STAT logs in to the Argos computer network each day and downloads all available locations and associated data for each user. These data are parsed and stored in a relational database and automatically backed up to an offsite location. A number of data filtering options are available, including setting maximum speed, time or distance between consecutive points, Argos location class, and turning angle. A variety of environmental data layers, including bathymetry, sea surface temperature, sea surface height, ocean currents and chlorophyll, can be sampled for all locations in the STAT database and can be downloaded and incorporated into tracking maps and animations. STAT also facilitates collaboration and the sharing of animal tracking information with the wider public and funding organizations. We hope that STAT will act as a catalytic foundation, fostering collaboration among users of satellite telemetry, and ensuring maximum value from these studies.
\end{abstract}

KEY WORDS: Satellite tracking $\cdot$ Argos $\cdot$ Wildlife telemetry $\cdot$ Biologging $\cdot$ Oceanography

Resale or republication not permitted without written consent of the publisher

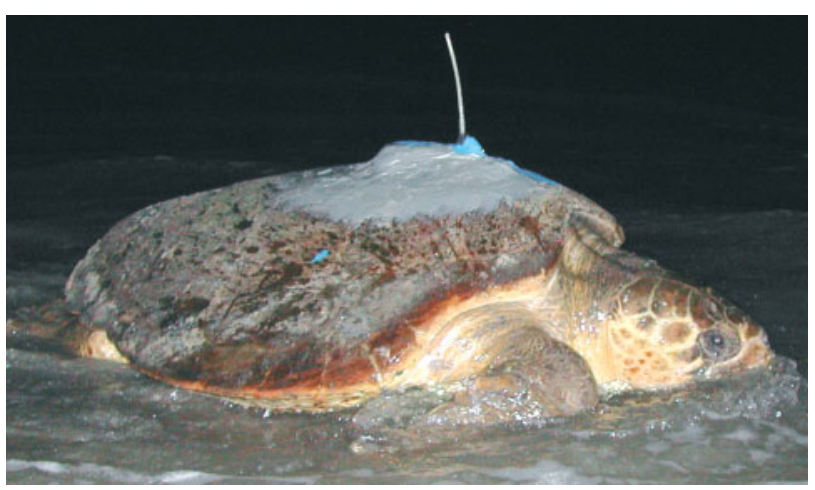

A female loggerhead returns to the sea equipped with a Sirtrack Kiwisat 101 satellite transmitter. She nested on Bald Head Island, NC, USA, on 1 August 2005. Data from the transmitter are processed by Service Argos and downloaded and mapped each day by the Satellite Tracking and Analysis Tool. The public can follow her progress at www.seaturtle.org/ tracking/Sumner along with $>100$ other tagged animals.

Photo: M. S. Coyne

\section{INTRODUCTION}

The development of satellite telemetry in the late 1980s allowed the first in-depth studies of animal movement patterns (Parmelee et al. 1985, DuronDeFrenne 1987, Fancy et al. 1988). Since then, Service Argos, a joint venture between the Centre National d'Etudes Spatiales (CNES, the French space agency), the National Aeronautics and Space Administration (NASA, USA) and the National Oceanic and Atmospheric Administration (NOAA, USA), has emerged as the predominant satellite-based system for tracking wildlife (Argos 1996). Polar orbiting satellites can 
locate Platform Terminal Transmitters (PTTs) allowing the generation of geographic location and limited transmission of sensor data. This is especially useful in the marine realm, where many vertebrate taxa migrate over wide spatial scales and where other tracking methodologies may be inadequate (Wilson et al. 2002).

Continuing improvements to the satellite network, transmitter miniaturization, and new deployment techniques have expanded the range of species that can be studied with satellite tracking, and declining transmitter costs have facilitated multi-year studies with larger sample sizes. These advances have transformed satellite telemetry from an experimental to an operational discipline. Yet the broad application of satellite telemetry presents 2 major challenges for the scientific community: effective data management and standardization. There was a 5-fold increase in the number of animals tracked using the Argos system from 1995 to 2005 (Fig. 1). As the number of studies continues to increase and their scope and complexity expands, researchers are increasingly faced with the need to effectively manage these datasets. Currently, the esoteric nature of satellite telemetry and other satellitebased data streams, combined with the lack of userfriendly tools for managing potentially large datasets, diminishes the use of these relatively costly data.

In addition, the broad array of methods and techniques used to process and analyze telemetry data greatly inhibit comparative studies, since results are rarely comparable across projects and publications. Much of the early literature from the 1990s is very difficult to compare to more recent studies, due to the development of new filtering algorithms and analytical tools used in this rapidly evolving field (Baduini \&

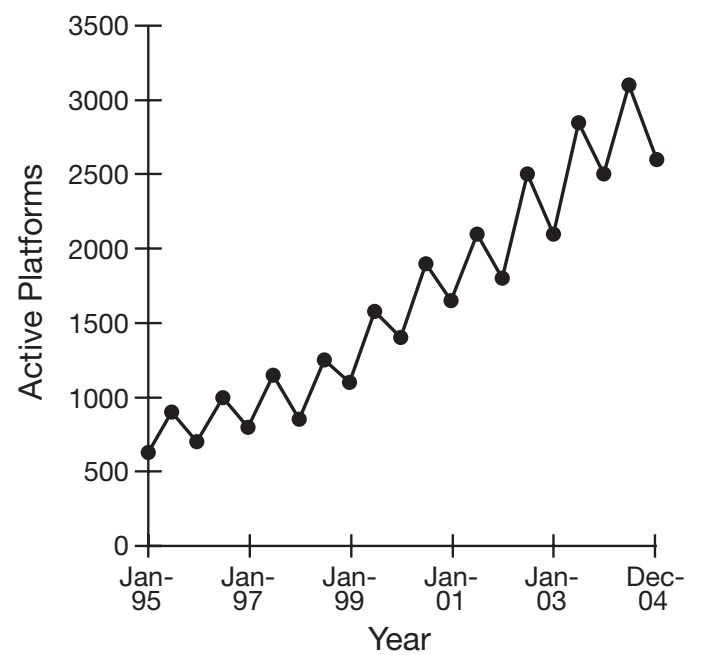

Fig. 1. Number of active animal-based Argos Platform Terminal Transmitters (PTTs) measured in winter and summer of each year from 1995 to December 2004. Data provided courtesy of Collecte Localisation Satellites (CLS)
Hyrenbach 2003). In those instances where researchers have come together to integrate their telemetry data, standardized data processing criteria will prove invaluable to facilitate comparative and synthetic studies across species and localities (Block et al. 2003, BirdLife 2004).

Despite the obvious power and advantages of the Argos system, the data generated are difficult for many biologists to fully exploit. Although steps have been taken to improve distribution mechanisms, the data stream still causes difficulty at various stages including downloading, collating, filtering and interpretation. In addition, integration of marine animal movements with other physical (e.g. remote sensing imagery) and anthropogenic (e.g. fishery distributions) datasets offers great opportunities for research and management, yet with enormous technical and computing challenges. Until recently, there was an obvious need for a facility designed by animal tracking biologists for animal tracking biologists including a set of standardized tools and techniques for data management and analysis. This resulted in the development of the Satellite Tracking and Analysis Tool (STAT), which is freely available online at www.seaturtle.org.stat. This article constitutes the first formal citable description of the system.

Organizations using Argos to track animals currently have the option to receive their data via a daily email update, a monthly CD-ROM, or via a Telnet network. Of these methods, Telnet is the most convenient, allowing users to log in and retrieve data on demand. Unfortunately, Argos only makes the previous $9 \mathrm{~d}$ of data available via Telnet, so users may miss some data if they are unable to log in to the Argos network for a longer time period. Additionally, the data format is not immediately compatible with any other application and must first be converted to another format, either manually or by desktop programs with various platform dependencies. Once the data are converted, users can analyze them in a statistical or GIS program of their choice.

\section{SYSTEM DESCRIPTION}

\section{Overview}

All STAT functions are executed using Perl scripts. Tracking data are retrieved from Argos each morning via Telnet (Fig. 2a). These data are parsed and stored in the STAT database. Additional value-added data are sampled from any available data layers for each tracking location and stored in the database. Data owners can download all data in the database to a common flat-file format. File transfer protocol (FTP) 


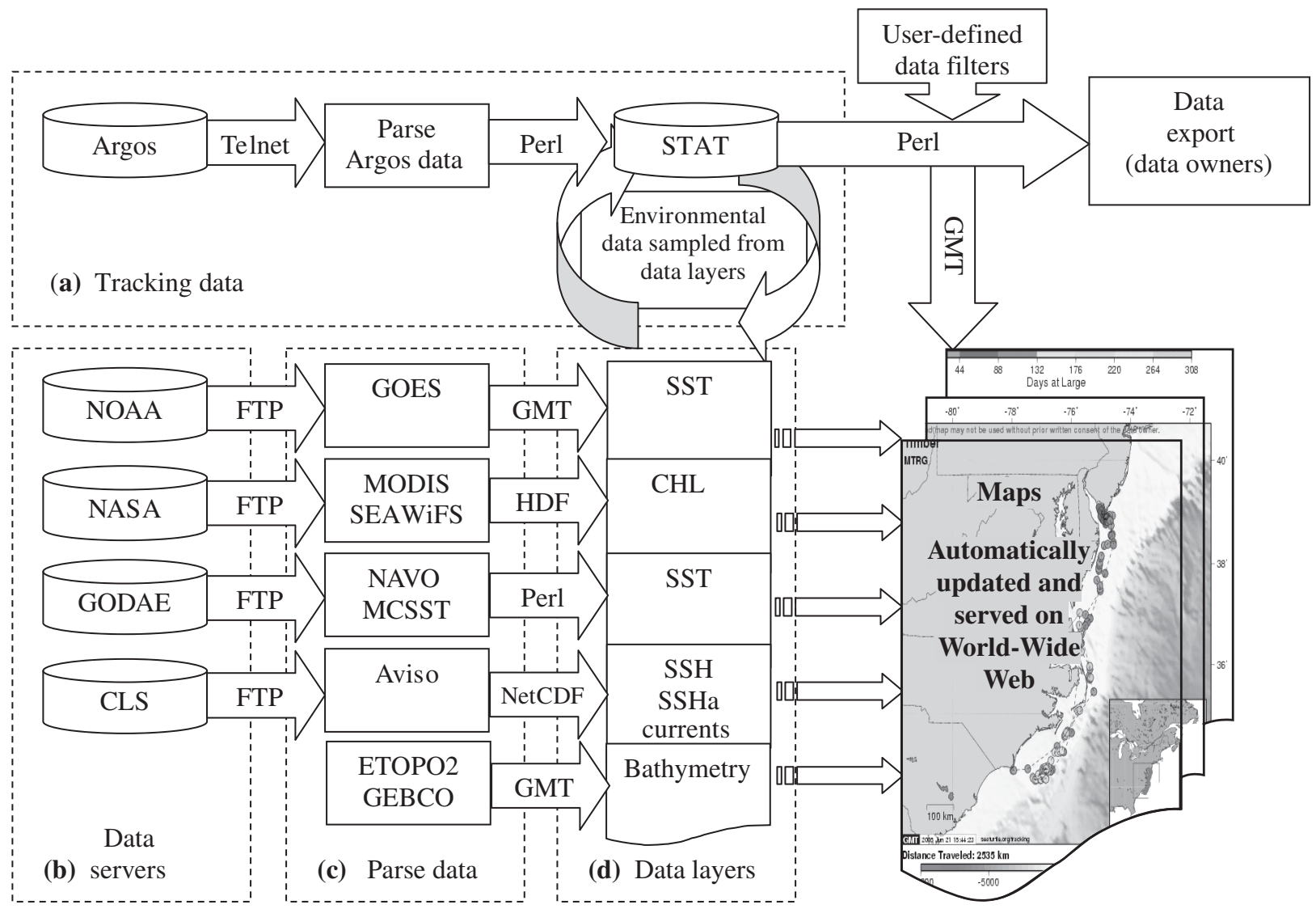

Fig. 2. Satellite Tracking and Analysis Tool (STAT): system overview

is used to obtain environmental data as it becomes available from data servers at NOAA, NASA, Collecte Localisation Satellites (CLS, a division of CNES) and the Global Ocean Data Assimilation Experiment (GODAE; Fig. 2b). Data from satellite based sensors and/or data compilation projects (Fig. 2c) are parsed using open source tools and utilities (Table 1), and converted to Generic Mapping Tools (GMT; available at http://gmt.soest.hawaii.edu/) grid format (Fig. 2d). These data layers can then be sampled or used to generate maps. Maps of each animal tracked and associated environmental data are automatically updated each day that new data are obtained.

\section{Data management}

STAT automates the process of retrieving and parsing Argos data, allowing users to spend more of their time on analysis and interpretation. The system logs in to the Argos computer network each day and downloads all available locations and associated data for each user for the previous $9 \mathrm{~d}$. These data are parsed and stored in a relational database. The program checks for any data that may have changed and updates the database, as Argos continues to process and refine location data for a period of time after data are initially collected. After each daily download all data are automatically backed up to an offsite location.

Users can upload archived Argos data collected before joining STAT. This is useful for users who receive the monthly Argos CD-ROM, which should represent the 'final' version of their data. The data from their monthly CD-ROM can be loaded and checked against existing data via checking routines built into STAT. The user has the option of inserting new data, updating changed data or deleting data in the database that are not on the monthly Argos CDROM.

STAT is entirely web-based and platform-independent, requiring only an Internet connection and a relatively modern browser. Access to the database is restricted and users may only view those datasets for which they have authorization. Once logged in, users can download their data for offline use in commaseparated values (CSV) format, which can be directly imported into most spreadsheet, statistics and GIS software packages. 
Table 1. Open-source tools and utilities used in the STAT system

\begin{tabular}{|llll|}
\hline Software & Version & Function & Source \\
\hline Perl & 5.6 .0 & Wrapper & perl.org \\
MySQL & 2.23 .53 & Database & mysql.com \\
NetCDF & 3.5 .1 & Data translation & fink.sourceforge.net \\
NCSA HDF & $4.1 \mathrm{r} 5$ & Data translation & fink.sourceforge.net \\
GMT & 3.4 .3 & Mapping and gridding & gmt.soest.hawaii.edu \\
Apache & 1.3 .33 & Web server & apache.org \\
GNU Wget & 1.8 .2 & FTP data retrieval & fink.sourceforge.net \\
curl & 7.10 .7 & FTP data retrieval & fink.sourceforge.net \\
\hline
\end{tabular}

\section{Data filtering and editing}

In addition to daily checks of the previous days' data and the potential to compare with the monthly data CDs provided by Argos, adequate biological interpretation requires the possibility of data filtering and editing. A number of options are available, including setting a maximum speed, time or distance between consecutive points, Argos location class, start and end date, and turning angle. The speed filter allows users to filter points based upon the maximum biologically relevant speed of the organism. Any combination of filter options can be saved for later use. In addition, ancillary data such as distance, speed and time between locations, cumulative time and distance from release, and distance from shoreline are included in all data downloads and are dynamically updated as data are filtered and edited.

Filtered data can be exported directly to SEATURTLE.ORG's Maptool, a web-enabled interface to GMT representing a collection of open source tools for manipulating geographic data sets and producing high quality maps (Wessel \& Smith 1998). The Maptool interface allows users to generate publication quality maps within the STAT online framework and has been empowering to users without the financial means to afford expensive GIS software and the associated hardware.

\section{Integrated environmental data}

A variety of environmental data layers are available in STAT for integration with animal tracking. These data are sampled for all locations in the STAT database and can be downloaded and incorporated into tracking maps and animations (Fig. 3).

Bathymetry. Both the General Bathymetric Chart of the Oceans (GEBCO) and the ETOPO2 Global 2Minute Elevations products are available within STAT (Fig. 3a). GEBCO is a global topographic dataset with one-minute $\left(1^{\prime}\right)$ spatial resolution (www.ngdc.noaa.gov/ $\mathrm{mgg} / \mathrm{gebco} /$ IOC, IHO, and BODC 2003). ETOPO2 is a gridded database of seafloor and land elevations covering the entire surface of the earth (www.ngdc.noaa.gov/mgg/ fliers/01mgg04.html). The database is based on a 2' latitude/longitude grid.

Sea surface temperature. Sea surface temperature (SST) data are gathered daily from the NOAA Geostationary Operational Environmental Satellites (GOES), and weekly and monthly from Advanced Very High Resolution Radiometer (AVHRR) satellite-based sensors (Fig. 3b). Near real time SST data from GOES are available from 5 May 2003 to the present at a spatial resolution of $6 \mathrm{~km}$ (http://podaac.jpl. nasa.gov/products/product190.html. The geostationary observations increase the probability of obtaining cloud-free pixels over most of the western hemisphere; $24 \mathrm{~h}$ composite gridded data are obtained from NOAA and gaps in each daily image are filled with data from images taken up to $2 \mathrm{~d}$ earlier and/or $2 \mathrm{~d}$ later, in an effort to obtain a completely cloud-free scene. These data are available from 180 to $30^{\circ} \mathrm{W}$ and $45^{\circ} \mathrm{S}$ to $60^{\circ} \mathrm{N}$. To complement GOES data, global SST data are obtained from GODAE, processed by the US Naval Oceanographic Office (www.usgodae.org; May et al. 1998). Global weekly and monthly gridded data layers are interpolated from multi-channel SST data (MCSST; derived from AVHRR) at a spatial resolution of $0.05^{\circ}$ (nominally $5.6 \mathrm{~km}$ ) and are available from 1998 to present. Tracks that fall entirely within the geographic domain of the GOES data set are mapped using those data. Tracks extending beyond the GOES domain are associated with the MCSST data.

Sea surface height and currents. Sea surface height (SSH), sea surface height anomaly (SSHa) and sea surface current (geostrophic velocity vector) data layers are obtained from the CNES/CLS Aviso/Altimetry project (www.aviso.oceanobs.com; Ducet et al. 2000). The data products used are from the Ssalto/Duacs multimission altimeter and include gridded sea level anomalies, gridded absolute dynamic topography and gridded geostrophic currents (Fig. 3c). These data have a spatial resolution of $1 / 3^{\circ}$ and are available in weekly time steps from 1998 to 2003 on, and in $3.5 \mathrm{~d}$ time steps from January 2004 to present. U and V components of the velocity vectors are sampled for all animal locations added to STAT and stored in the STAT database for analysis and download.

Chlorophyll. Global weekly and monthly chlorophyll data layers are obtained from NASA's Ocean Color project SeaWiFS and MODIS satellite-based sensors (http://oceancolor.gsfc.nasa.gov; McClain et al. 2004). Chlorophyll data are available from SeaWiFS at a 9 km spatial resolution from 1998 through June 2002 

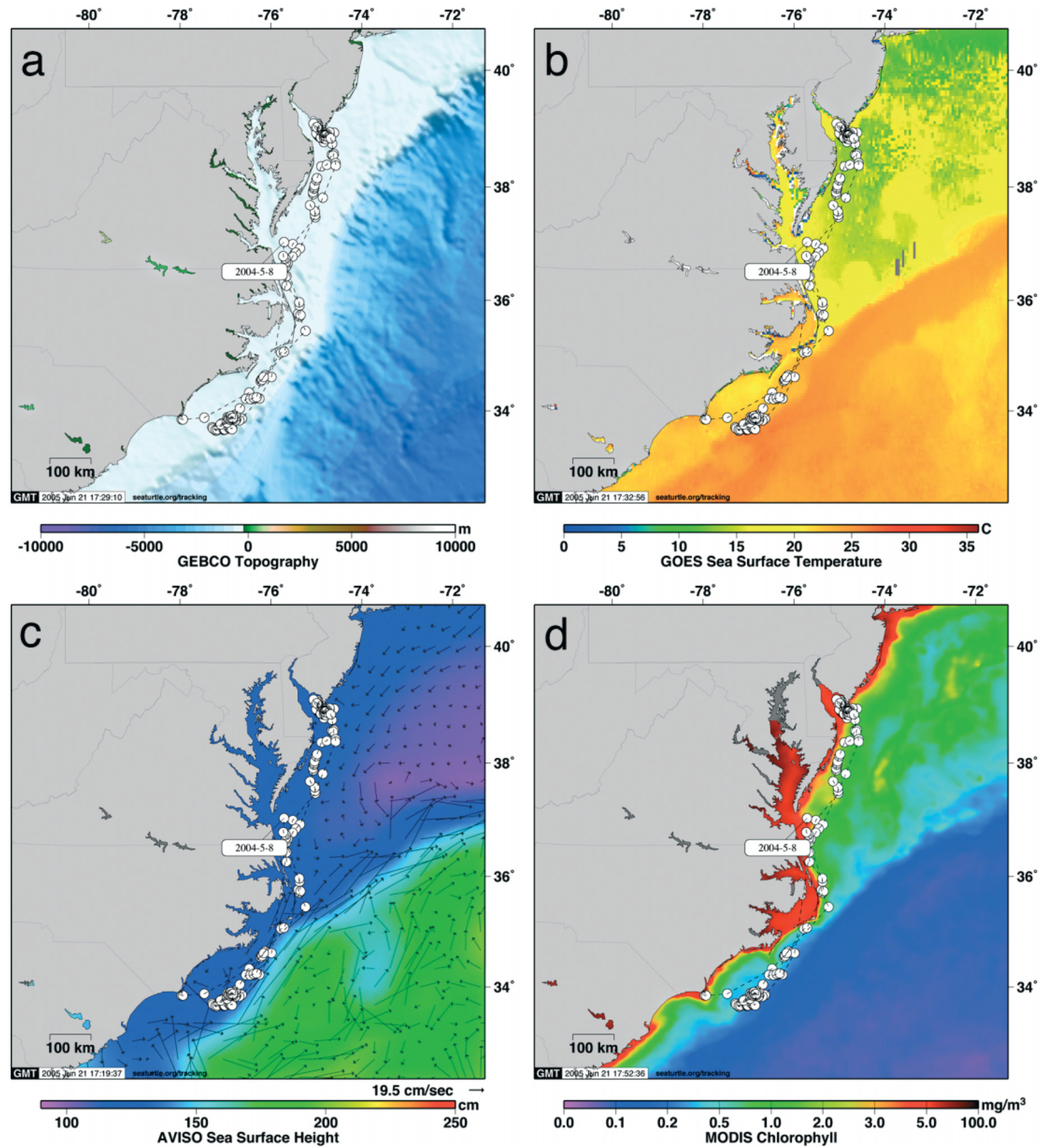

Fig. 3. Example outputs from the STAT package for a loggerhead turtle tracked from its nesting site at Bald Head Island, North Carolina $\left(77.96^{\circ} \mathrm{W}, 33.84^{\circ} \mathrm{N}\right)$ to Delaware Bay and back to an overwintering site off the nesting beach. Locality versus (a) GEBCO bathymetry, (b) NOAA GOES sea surface temperature, (c) Aviso geostrophic currents and sea surface height, and (d) MODIS chlorophyll. Note how sea surface temperature (SST), sea surface height (SSH) and chlorophyll highlight the passage of the Gulf Stream through the region 
and thereafter from MODIS at $4 \mathrm{~km}$ spatial resolution (Fig. 3d).

Visualizing data. STAT uses GMT to generate a suite of map products that are automatically updated each day as new data become available for each tracked animal. Users can set a variety of preferences that determine the appearance of the map for each tracked animal and the method by which tracking data are filtered, and that include any of the environmental data layers illustrated in Fig. 3. High-resolution, publication quality versions of each map are also available. In addition, summary tables, histograms and graphs are automatically generated to show the distribution of Argos location classes, displacement from release, exposure to environmental variables over time and a summary of the number of days spent within geopolitical boundaries. Simple animations of animal movement through time are also generated automatically. Animations with specific parameters and including any of the dynamic environmental layers mentioned above are available upon request.

\section{PERSPECTIVES}

\section{Education and public outreach}

STAT facilitates data sharing and visualizing among collaborators but also facilitates sharing of exciting animal tracking information with the general public and funding organizations. All, some or none of the tracked animals of each project can be shared publicly on SEATURTLE.ORG to inform and educate the public about animal tracking projects. Visitors to the website (www.seaturtle.org/tracking/) can subscribe to email updates. On 25 August 2005, 280 tracks were available online; the tracking website currently receives $>150000$ visits per month, and has had >2 million visits since its inception in July 2003. A limited subset of data from any tagged animal can optionally be shared with teachers that register on SEATURTLE.ORG for educational activities in the classroom. The intense public interest in large vertebrates tracked with STAT has attracted attention from the mass media. The fact that the public can track study animals online in near real time, combined with the availability of attractive maps, has lead to numerous articles in national and international television, radio, print and online news outlets.

\section{Outlook}

At the time of writing (25 August 2005) there were more than 590 animal tracks in the STAT database, and although it began with sea turtles, it currently includes 36 organizations around the world and $>57$ different projects on marine mammals, birds and sharks. It is important to note that many of the tools in STAT can also be used in terrestrial tracking applications.

Planned improvements include the addition of new environmental data layers; derived data layers (environmental gradients, frontal zones, distance from environmental features); and new analytical tools (home range, spatial statistics, movement classification algorithms). Existing facilities will be improved to provide interactive visualization and smart data filtering. It is hoped that the addition of metadata support will encourage investigators to begin to use the system as a data clearinghouse linked with existing efforts such as the Census of Marine Life's Ocean Biogeographic Information System (http://seamap.env.duke.edu/; Halpin et al. 2004) and the Global Ocean Observing System (http://ioc.unesco.org/goos; Nowlin et al. 2001). In general, it is hoped that STAT will foster collaboration among researchers utilizing satellite telemetry and help ensure maximum value from these studies.

Acknowledgements. We thank A. Broderick and L. Hawkes of the Marine Turtle Research Group and M. Godfrey of the North Carolina Wildlife Resources Commission for providing the track and maps used as examples. We thank Anne-Marie Breonce of CLS for providing data on the number of active animal platforms. B. Godley received funding from the Natural Environment Research Council (UK) during the development of this manuscript. Helpful comments on an earlier draft were provided by J. Blumenthal, A. Broderick, W. Fuller, M. Godfrey, L. Hawkes, M. Witt, D. Rowat, T. Tucker and 4 anonymous referees. Finally, many thanks to all of the founding users of STAT, who allowed the initiative to attain critical mass and helped to refine its functionality by their suggestions, and to the oceanographic community for their far-sighted open-access ethos.

\section{LITERATURE CITED}

Argos (1996) User's manual. CLS/Service Argos, Toulouse

Baduini CL, Hyrenbach KD (2003) Biogeography of Procellariiform foraging strategies: does ocean productivity influence provisioning? Mar Ornithol 31:101-112

BirdLife International (2004) Tracking ocean wanderers: the global distribution of albatrosses and petrels. BirdLife International, Cambridge

Block BA, Costa DP, Boehlert GW, Kochevar RE (2003) Revealing pelagic habitat use: the Tagging of Pacific Pelagics Program. Oceanol Acta 25:255-266

Ducet N, Le Traon PY, Reverdin G (2000) Global high resolution mapping of ocean circulation from Topex/Poseidon and ERS-1 and -2. J Geophys Res 105:19477-19498

Duron-DuFrenne M (1987) Premier suivi par satellite en Atlantique d'une tortue luth Dermochelys coriacea. CR Acad Sci Ser III 304:399-402

Fancy SG, Pank LF, Douglas DC, Curby CH, Garner GW, Amstrup SC, Regelin WL (1988) Satellite telemetry: a new 
tool for wildlife research and management. US Fish Wildl Serv Res Publ 172:1-54

Halpin P, Read A, Crowder L, Best B, Hyrenbach D, Freeman S (2004) OBIS-SEAMAP: developing a biogeographic research data commons for the conservation of marine mammals, sea birds and sea turtles. In: Proceedings Ocean Biodiversity Informatics, International Conference on Marine Biodiversity Data Management, Hamburg, Germany, 29 Nov-1 Dec 2004

IOC, IHO, BODC (2003) Centenary Edition of the GEBCO Digital Atlas. British Oceanographic Data Centre, Liverpool

May DA, Parmeter MM, Olszewski DS, McKenzie BD (1998) Operational processing of satellite sea surface temperature retrievals at the Naval Oceanographic Office. Bull Am Meteorol Soc 79:397-407

McClain CR, Feldman GC, Hooker SB (2004) An overview of

Editorial responsibility: Otto Kinne (Editor-in-Chief),

Oldendorf/Luhe, Germany the SeaWiFS project and strategies for producing a climate research quality global ocean bio-optical time series. Deep Sea Res II 51:5-42

Nowlin WD, Briscoe M, Smith N, McPhaden MJ, Roemmich D, Chapman P, Grassle JF (2001) Evolution of a sustained ocean observing system. Bull Am Meteorol Soc 82: $1369-1376$

Parmelee DF, Parmelee JM, Fuller M (1985) Ornithological investigations at Palmer Station: the first long-distance tracking of seabirds by satellites. Antarct J US 19:162-163

Wessel P, Smith WHF (1995) New version of the Generic Mapping Tools released. EOS Trans Am Geol Union 76: 329

Wilson RP, Grémillet D, Syder J, Kierspel MAM and 7 others (2002) Remote-sensing systems and seabirds: their use, abuse and potential for measuring marine environmental variables. Mar Ecol Prog Ser 228:241-261

Submitted: June 23, 2005; Accepted: September 1, 2005

Proofs received from author(s): September 27, 2005 